\title{
US becoming more accepting of medical marijuana
}

A cancer patient in Alaska with a medical marijuana identification card can grow six cannabis plants for personal medical use. A person in Delaware can't grow it, but by next year might be able to buy marijuana at a state-sanctioned "compassion centre." In California, patients can grow their own marijuana or buy it from a wide range of largely unregulated collectives and cooperatives.

Check back in six months or a year, and the patchwork of state laws governing medical use of marijuana in the United States could well be different. State by state, month by month, Americans are taking a more accepting approach toward medical marijuana. And there is a newer movement afoot to legalize marijuana for recreational purposes too.
Twenty states and the District of Columbia - covering $40 \%$ of the US population - now allow the use of marijuana for medical reasons, with Illinois and New Hampshire enacting laws just this summer. Voters in Colorado and Washington have gone a step further and approved the recreational use of marijuana. Legalization advocates expect that by 2017 as many as five more states will do the same.

All this activity is in defiance of a federal law that bans marijuana, classified as a Schedule I drug that has "no currently accepted medical use" and "high potential for abuse." President Barack Obama, however, has directed federal officials to take a hands-off approach to people who use medical marijuana in compliance with state laws. And in August, the US Justice Department released long-awaited guidance indicating that the federal government won't challenge state laws that legalize recreational use as long as the states strictly regulate sale and distribution.

Richard Bonnie, a law professor at the University of Virginia in Charlottesville who has tracked the history of marijuana, says acceptance of marijuana is growing at a surprising pace. "I think it is extremely important to assure that any efforts to liberalize access to marijuana are designed and regulated carefully to protect the public health," he says. "Careful policy design can avoid replicating our experiences with alcohol and tobacco."

Physicians have a voice in this debate, but their involvement in the regulatory details has been limited and varies from state to state. In Michigan and New Mexico, for example, physicians sit on panels that consider requests to expand the

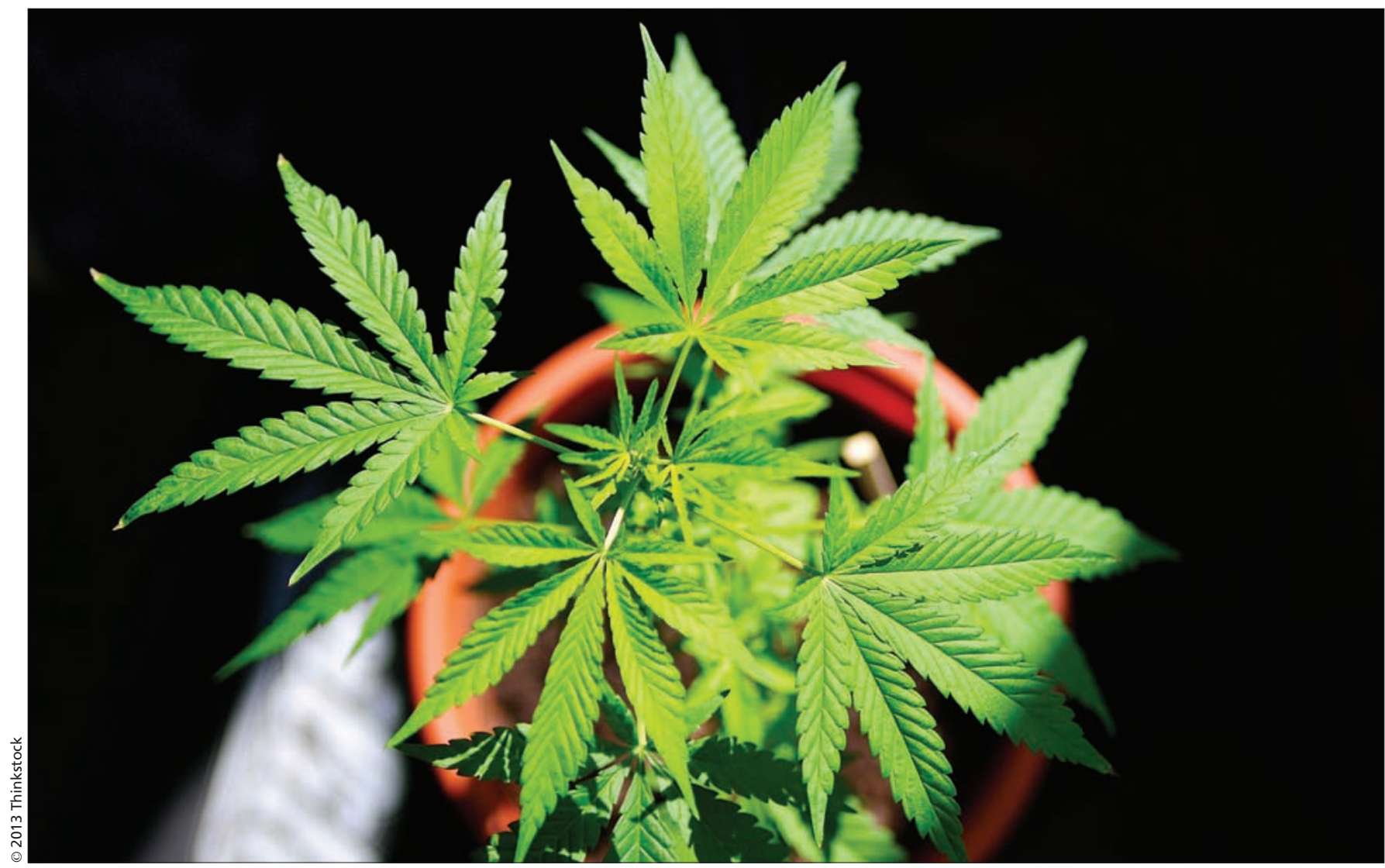

A person in Alaska with a medical marijuana identification card can grow six cannabis plants for personal medicinal use. 
range of conditions or diseases for which medical marijuana is available. In Massachusetts, doctors were vocal on both sides of a debate over minors' access to medical marijuana.

Because of the federal ban on marijuana, physicians can't prescribe it. But they can make a judgment that a patient would benefit from it, and patients in states where medical marijuana is condoned can use that recommendation to obtain an ID card that allows them to get marijuana. State rules vary on what kind of physician-patient relationship is required before doctors can make such a recommendation.

Zach Walsh, codirector of the University of British Columbia's Centre for the Advancement of Psychological Science and Law in Vancouver, predicts that, in both the US and Canada, the reluctance of some physicians to act as gatekeepers for access to cannabis will disappear as the stigma associated with marijuana decreases and more is known about its efficacy.

Walsh, who has studied medical cannabis use in Canada, envisions a time when physicians will recommend it just as they might suggest Aspirin. "You'll find a pretty strong relationship between awareness of medical cannabis and acceptance of it," he says.

Medical societies in both countries are more wary. The American Medical Association opposes the legalization of marijuana but has recommended that its status as a Schedule I drug be reviewed to encourage research. The Canadian Medical Association's policy states that it "strongly opposes the use of marijuana for medical reasons in the absence of supporting scientific evidence."

Karen O'Keefe of the Marijuana Policy Project, which advocates legalization of marijuana, says states are functioning as "laboratories of democracy" and learning from one another as they tailor their approaches to local concerns.

But Kevin Sabet, a former government drug policy adviser who helped found Smart Approaches to Marijuana, which opposes legalization, worries that acceptance of marijuana is growing even as more is being learned about its dangers. He predicts that the future of legalization in the US will hinge on results in Colorado and Washington, where regulated recreational use is just now rolling out.

"If it goes badly," Sabet says, "then we're going to see a change in attitude. But we may not know what happens for five or six years, and by the time the statistics come in, we might have more states that have legalized it." - Nancy Benac, Washington, DC

CMAJ 2013. DOI:10.1503/cmaj.109-4612 